\title{
Gestational Diabetes Mellitus: Challenges in Diagnosis and Management
}

\author{
${ }^{1}$ Ruchika Garg, ${ }^{2}$ Priyankur Roy, ${ }^{3}$ Prabhat Agrawal, ${ }^{4}$ Ashish Gautam, ${ }^{5}$ Himani Goel \\ ${ }^{6}$ Shaheen Hokabaj, ${ }^{7}$ Neharika Malhotra
}

\begin{abstract}
Diabetes mellitus is a chronic illness that requires continuing medical care and ongoing patient self-management education and support to prevent acute complications and to reduce the long-term complications. Moderate-to-severe maternal hyperglycemia in pregnancy has unique diabetes-related risks to mother and her unborn baby. So, gestational diabetes mellitus (GDM) is a carbohydrate intolerance that has been diagnosed for the first time during pregnancy. Approximately, $7 \%$ of pregnancies are affected by GDM.

Patients with GDM are at higher risk for excessive weight gain, preeclampsia, and cesarean sections. Infants born to mothers with GDM are at higher risk for macrosomia, birth trauma, and shoulder dystocia. After delivery, these infants have a higher risk of developing hypoglycemia, hypocalcemia, hyperbilirubinemia, respiratory distress syndrome, polycythemia and subsequent obesity, and type II diabetes.

The management of GDM is very important, and its management remains a challenge for obstetricians and endocrinologists. Medical nutritional therapy (MNT) is the initial and most common therapy that suffices for GDM. Pharmacological therapy becomes necessary, and the treatment of choice is human insulin. Oral hypoglycemic agents have also reached the high tables in the management of GDM. Glyburide and metformin have been found to be safe, effective, and economical for the treatment of gestational diabetes.
\end{abstract}

Keywords: Gestational diabetes mellitus, Glucose intolerance, Insulin, Medical nutritional therapy, Oral hypoglycemic agents.

How to cite this article: Garg R, Roy P, Agrawal P, Gautam A, Goel H, Hokabaj S, Malhotra N. Gestational Diabetes Mellitus: Challenges in Diagnosis and Management. J South Asian Feder Obst Gynae 2018;10(1):54-60.

\footnotetext{
${ }^{1,3,4}$ Associate Professor, ${ }^{2}$ Tutor, ${ }^{5}$ Junior Resident, ${ }^{6}$ Clinical Fellow, ${ }^{7}$ Consultant

${ }^{1,5}$ Department of Obstetrics and Gynecology, Sarojini Naidu Medical College, Agra, Uttar Pradesh, India

2Department of Obstetrics and Gynecology, North Bengal Medical College \& Hospital, Siliguri, West Bengal, India

${ }^{3,4}$ Department of Medicine, Sarojini Naidu Medical College, Agra Uttar Pradesh, India

${ }^{6}$ Department of Obstetrics and Gynecology, SNEH Infertility Centre, Ahmedabad, Gujarat India

${ }^{7}$ Department of Obstetrics and Gynecology, Rainbow IVF, Agra Uttar Pradesh, India

Corresponding Author: Ruchika Garg, Associate Professor Department of Obstetrics and Gynecology, Sarojini Naidu Medical College, Agra, Uttar Pradesh, India, e-mail: ruchikagargagra@ gmail.com
}

\section{Source of support: Nil}

\section{Conflict of interest: None}

Date of received: 15 January 2018

Date of acceptance: 25 February 2018

Date of publication: May 2018

\section{INTRODUCTION}

Diabetes mellitus is a chronic illness that requires continuing medical care and ongoing patient self-management education and support to prevent acute complications and to reduce the long-term complications. Gestational diabetes mellitus, by definition, is any degree of glucose intolerance with onset or first recognition during pregnancy. ${ }^{1}$ Gestational diabetes mellitus affects roughly $7 \%$ of pregnancies with an incidence of more than 200,000 cases per year. ${ }^{2}$ It contributes to about $90 \%$ of diabetes complicating pregnancy. ${ }^{3}$ It imposes risks for both mother and fetus, some of which continues throughout the life of mother and child. Immediate maternal complications include preeclampsia, need for cesarean section, and polyhydramnios. ${ }^{4}$ Complications in the baby include hyperinsulinemia, macrosomia, shoulder dystocia, neonatal hypoglycemia, and respiratory distress syndrome.

Women with GDM have 40 to $60 \%$ chance of developing diabetes mellitus over 5 to 10 years after pregnancy. ${ }^{1}$ Gestational diabetes mellitus also increases the risk of obesity and glucose intolerance in the offspring. ${ }^{5}$ It is therefore, an important public health issue that has major repercussions for both mother and offspring. Detection of GDM thus provides a window of opportunity to intervene and reduce adverse perinatal outcomes. ${ }^{6}$

\section{Epidemiology}

The prevalence of GDM depends on which population was being studied and what screening strategies and diagnostic criteria were used. The prevalence in the United Kingdom, USA, and among European countries was estimated to be 5,3 to 7 , and 2 to $6 \%$ respectively. Higher prevalence of GDM was noted in African, Asian, Indian, and Hispanic women. ${ }^{7}$

The International Diabetes Federation estimates that as of $2015,16.2 \%$ of women with live births had some form 
of hyperglycemia in pregnancy, $85 \%$ of which were due to gestational diabetes. ${ }^{8}$ Asian women are more prone to develop GDM than European women, and Indian women have 11-fold increased risk of developing glucose intolerance in pregnancy compared with Caucasian women. ${ }^{9}$ In the Indian context, the prevalence of GDM is steadily increasing from $2 \%$ in 1982 to $7.2 \%$ in 1991 and which has doubled to $16.55 \%$ in 2002. In 2013, 6 million women in India had some form of hyperglycemia in pregnancy, of which $90 \%$ were GDM. ${ }^{10,11}$ Gestational diabetes mellitus is usually asymptomatic and is most commonly diagnosed by routine screening during pregnancy. Unfortunately, there is little agreement on the best screening and diagnostic tests for GDM.

It is estimated that 4 million women are affected by GDM in India, ${ }^{12}$ at any given time point. The prevalence of gestational diabetes has been reported to range from $3.8 \%$ in Kashmir $^{13}$ to $6.9 \%$ in Mysore, ${ }^{14} 9.5 \%$ in western India, ${ }^{15}$ and $17.9 \%$ in Tamil Nadu. ${ }^{4}$ In more recent studies, using different criteria, prevalence rate as high as $35 \%$ from Punjab ${ }^{16}$ and $41 \%$ from Lucknow ${ }^{17}$ has been reported (Fig. 1). Studies on prevalence of GDM in India are summarized in Table 1.

\section{SCREENING}

The first screening test for GDM, proposed in 1973, consisted of 1-hour $50 \mathrm{gm}$ oral glucose tolerance test (OGTT) ${ }^{18}$ While some guidelines recommend universal screening, others exempt those patients who are categorized as low risk. Evidence suggests that universal screening improves pregnancy outcomes compared with selective screening (Table 2). ${ }^{19}$

Although some experts recommend against screening low-risk patients routinely, ${ }^{2}$ selective screening could miss approximately $4 \%$ of patients with GDM. ${ }^{22}$ Pregnant women with high risk factors for GDM should be screened for GDM as soon as possible, preferably during their first antenatal visit. If negative, they should be retested at the beginning of their third trimester between 24 and 28 weeks of gestation. When universal screening

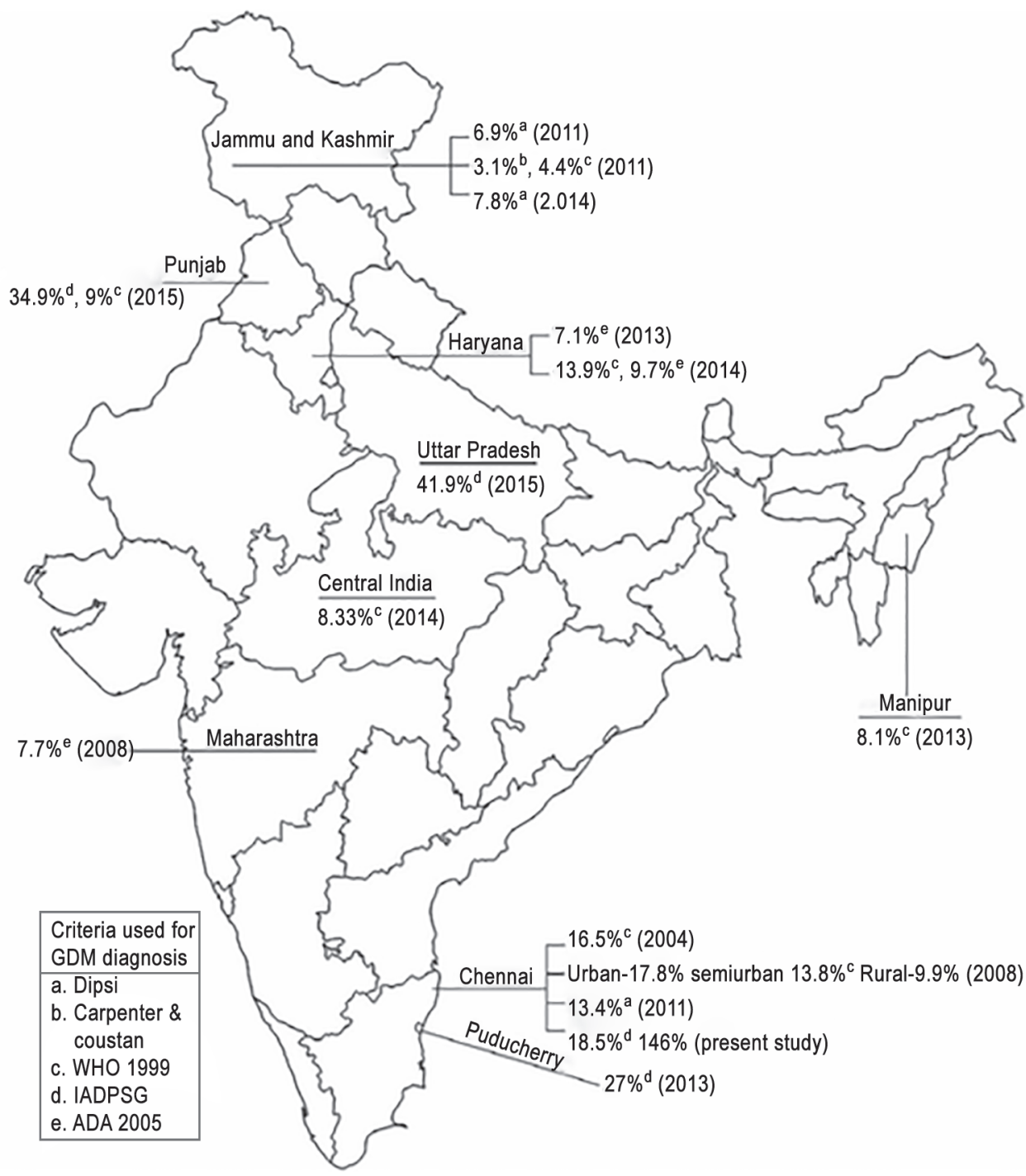

Fig. 1: Graphical representation of GDM prevalence across India 
Table 1: Various studies and methods used in detection of GDM

\begin{tabular}{|c|c|c|c|c|}
\hline Author name & City/state & $\begin{array}{l}\text { Sample } \\
\text { size }\end{array}$ & Prevalence (\%) & $\begin{array}{l}\text { Criteria used for } \\
\text { GDM diagnosis }\end{array}$ \\
\hline Seshiah et al $^{4}$ & Government Maternity Hospital, Chennai & 3,674 & 16.5 & WHO 1999 \\
\hline Seshiah et al & Chennai & 4,151 & $\begin{array}{l}\text { Urban } 17.8 \text {, semi-urban } \\
13.8 \text {, rural } 9.9\end{array}$ & WHO 1999 \\
\hline Swami et al ${ }^{13}$ & Maharashtra & 1,225 & 7.7 & ADA 2005 \\
\hline Seshiah et al & Chennai & 1,463 & 13.4 & DIPSI \\
\hline Wahi et al & Government Medical College, Jammu & 2,025 & 6.9 & DIPSI \\
\hline Nayak et al & Pondicherry Institute of Medical Science & 304 & 27 & IADPSG \\
\hline Vanlalhruaii et al & RIMS, Manipur & 300 & 8.1 & ADA 2005 \\
\hline Rajput et al & $\begin{array}{l}\text { Post Graduate Institute of Medical Sciences, } \\
\text { Haryana }\end{array}$ & 607 & 7.1 & ADA 2005 \\
\hline Zargar et al & Sher-i-Kashmir Institute of Medical Sciences & 2,000 & $\begin{array}{l}3.1 \\
4.4\end{array}$ & $\begin{array}{l}\text { Carpenter and } \\
\text { Coustan WHO } \\
1999\end{array}$ \\
\hline Raja et al $^{12}$ & Government Medical College, Srinagar & 306 & 7.8 & DIPSI \\
\hline Rajput et al & Rural Haryana & 900 & $\begin{array}{l}13.9 \\
9.7\end{array}$ & $\begin{array}{l}\text { WHO } 1999 \\
\text { ADA } 2005\end{array}$ \\
\hline Kalyani et al & Central India & 300 & 8.33 & WHO 1999 \\
\hline Arora et al ${ }^{16}$ & Ludhiana, Punjab & 5,100 & $\begin{array}{l}34.9 \\
9\end{array}$ & $\begin{array}{l}\text { IADPSG } \\
\text { WHO } 1999\end{array}$ \\
\hline Gopalakrishnan et $\mathrm{al}^{17}$ & SGPIMS, Lucknow & 332 & 41.9 & IADPSG \\
\hline
\end{tabular}

WHO: World Health Organization; ADA: American Diabetes Association; IADPSG: International Association of Diabetes in Pregnancy Study Groups; DIPSI: Diabetes in Pregnancy Study Group India

Table 2: Categorizing groups at risk for GDM ${ }^{20,21}$

\begin{tabular}{ll}
\hline Risk & \\
category & Clinical characteristics \\
\hline High risk & - Obesity \\
& - Diabetes in first-degree relative \\
& - Current glycosuria \\
& - Previous history of GDM or glucose intolerance \\
& - Previous poor obstetric outcome (unexplained \\
& intrauterine fetal death) \\
& - Previous history of macrosomia fetus or \\
& unexplained polyhydramnios \\
- Age <25 years & \\
- & Belongs to low-risk ethnic groups (ethnic groups \\
& other than Hispanic, African-American, South \\
& Asian, East Asian, Pacific Islander, or Australian) \\
& - No diabetes in first-degree relative but present \\
& in distant relatives \\
& No history of abnormal glucose tolerance \\
& previously \\
- Normal prepregnancy weight and pregnancy & weight gain \\
& - Previous living birth with no complications \\
\hline
\end{tabular}

is implemented, patients with no recognized risk factors for GDM also undergo a 1-hour glucose challenge test (GCT) at 24 to 28 weeks of pregnancy. ${ }^{22}$

Fasting plasma glucose and postprandial plasma glucose have been shown to have low sensitivity as screening tests for GDM, and therefore, they are not recommended for screening. ${ }^{23}$ In general, there are two approaches to the evaluation of women for GDM: The onestep approach and the two-step approach. In the one-step approach, a diagnostic OGTT is performed without prior glucose screening. This approach is cost-effective. In the two-step approach, initial screening involves the GCT, which measures glucose concentration 1 hour after a $50 \mathrm{gm}$ oral glucose load. The diagnostic OGTT performed only in the subset of women found to have glucose concentration values exceeding the normal levels.

\section{DIAGNOSTIC CRITERIA}

While performing GCT, when the threshold for GCT is $>140 \mathrm{mg} / \mathrm{dL}$, the sensitivity is $80 \%$; when it is $130 \mathrm{mg} / \mathrm{dL}$, the sensitivity increases to $90 \% .{ }^{1}$ Whichever approach is used, the diagnosis of GDM is established only after performing an OGTT.

There are two major diagnostic criteria for the 3-hour 100-gm OGTT used: Carpenter-Coustan criteria and the National Diabetes Data Group (NDDG) criteria. The NDDG criteria were found to be less sensitive in diagnosing GDM and in predicting incidence of perinatal morbidities. ${ }^{24}$ Alternatively, the American Diabetes Association (ADA) criteria for GDM diagnosis rely on a 75-gm glucose load and consider fasting serum glucose concentration, 1-hour glucose concentration, and 2-hour glucose concentration..$^{25}$ Again, two or more abnormal values are required for diagnosis. Although all these major criteria require two or more abnormal values for diagnosis, studies have shown that a single abnormal value is significantly associated with increased risk of perinatal morbidities. ${ }^{26}$ 
Gestational Diabetes Mellitus

Table 3: Diagnostic criteria for GDM with their respective glucose values

\begin{tabular}{lllll}
\hline Diagnostic criteria & Fasting $(\mathrm{mg} / \mathrm{dL})$ & 1-hour $(\mathrm{mg} / \mathrm{dL})$ & 2-hours $(\mathrm{mg} / \mathrm{dL})$ & 3-hours $(\mathrm{mg} / \mathrm{dL})$ \\
\hline 100-gm OGTT Carpenter-Coustan (two or more abnormal) & 95 & 180 & 155 & 140 \\
100-gm OGTT NDDG (two or more abnormal) & 105 & 190 & 165 & $145(8.1)$ \\
75-gm OGTT ADA (two or more abnormal) & 95 & 180 & 155 & - \\
75-gm OGTT WHO (one or more abnormal) & $92-125$ & $\geq 180$ & $153-199$ & - \\
\hline
\end{tabular}

The World Health Organization (WHO) recommends using a 75-gm glucose tolerance test for screening and diagnosis. When the WHO criteria are used, approximately twice as many patients will be diagnosed with GDM compared with other criteria. However, there is no proven additional clinical benefit with the use of $\mathrm{WHO}$ criteria (Table 3$){ }^{27}$

\section{TREATMENT}

Evidence shows that screening and treating GDM leads to reduction of perinatal morbidity and improvement in the post-delivery outcomes. ${ }^{28}$ Good glycemic control has been shown to reduce adverse outcomes in the babies as well as the pregnant women with GDM. ${ }^{29}$

\section{Target Glucose Values}

Experts recommend that women with GDM should maintain the following capillary blood glucose values: Fasting blood sugar $<95 \mathrm{mg} / \mathrm{dL}$, 1-hour postprandial glucose $<140 \mathrm{mg} / \mathrm{dL}$, and 2-hour postprandial glucose $<120 \mathrm{mg} / \mathrm{dL}^{1}{ }^{1}$ Other recommendations suggest maintaining fasting glucose levels between 90 and $99 \mathrm{mg} / \mathrm{dL}$, 1-hour postprandial glucose levels of $<140 \mathrm{mg} / \mathrm{dL}$, and 2-hour postprandial glucose levels ranging between 120 and $127 \mathrm{mg} / \mathrm{dL}^{30}$

Even if the recommended levels of glycemic control cannot be achieved, any improvement can be beneficial in reducing the perinatal complications, owing to the increased glucose levels. ${ }^{31}$ Despite the benefits of glycemic control, studies on the contrary have shown that very low target glucose values $(<87 \mathrm{mg} / \mathrm{dL})$ are associated with increased rates of intrauterine fetal demise. ${ }^{32}$

\section{Medical Nutrition Therapy}

The first line of management for women with GDM is dietary modification. Evidence indicates that MNT is effective in reducing pregnancy and perinatal complications and also in attaining glycemic control. ${ }^{33}$ According to ADA recommendations, carbohydrate intake should be approximately $40 \%$ of total calorie intake and should be selected from foods with low glycemic index values. ${ }^{34}$

In pregnant women of normal body weight (BMI between 18.5 and 24.9), the recommendation is to consume 30 to $32 \mathrm{kcal} / \mathrm{kg}$ body weight. Those who are overweight
(BMI between 25 and 29.9) should ingest approximately $25 \mathrm{kcal} / \mathrm{kg}$ body weight and in obese women (BMI>30), consumption should be 12 to $15 \mathrm{kcal} / \mathrm{kg}$ body weight. ${ }^{35} 75$ to $80 \%$ of women with GDM become euglycemic by following these caloric distribution guidelines. Caloric restriction should be approached cautiously, because studies show that elevated maternal ketone levels are associated with impaired psychomotor development. $^{36}$

Compared with diet alone, exercise with dietary modifications has been found to lead to improved glycemic control. ${ }^{37}$ The proposed mechanism for such an improvement in glycemic control is heightened sensitivity of peripheral tissues to insulin. A supervised home-based cycling program was helpful in maintaining normal postprandial glucose levels in pregnant women with diet-controlled GDM. ${ }^{38}$

Based on the available evidence on the benefits of exercise in managing GDM, ADA recommends moderate exercise programs for women without medical or obstetrical complications. For the general population, experts tend to recommend exercising three or more times a week for about 30 minutes.

\section{Pharmacotherapy}

Pharmacological intervention in the management of GDM is usually employed when women fail to meet established goals with conventional therapy of diet and exercise. It is also indicated that elevated fasting glucose levels occur while on conventional therapy, because dietary modification has limited effect on these levels.

The pharmacological options mainly include insulin or oral hypoglycemic agents (Metformin and Glyburide). ${ }^{39,40}$

\section{Insulin}

Insulin therapy is the most commonly used pharmacotherapy once MNT fails to achieve desired outcomes. Insulin regimens often include intermediate-acting insulins, such as isophane and short-acting agents, such as regular recombinant insulin (Humulin R). Pharmacotherapy can also involve the insulin analogs Aspart and Lispro. Insulin therapy decreases the frequency of fetal macrosomia and the risk of perinatal morbidity. ${ }^{41}$ 
Table 4: Glucose level cut-off points requiring insulin initiation in GDM

\begin{tabular}{llll}
\hline & $\begin{array}{l}\text { Fasting } \\
(\mathrm{mg} / \mathrm{dL})\end{array}$ & $\begin{array}{l}\text { 1-hour } \\
\text { postprandial } \\
(\mathrm{mg} / \mathrm{dL})\end{array}$ & $\begin{array}{l}\text { 2-hour } \\
\text { postprandial } \\
(\mathrm{mg} / \mathrm{dL})\end{array}$ \\
\hline ACUidelines & $>95$ & $>130-140$ & $>120$ \\
ADA & $>90-99$ & $>140$ & $>120-127$ \\
\hline
\end{tabular}

Studies have shown that insulin analogs (Lispro and Aspart) are more effective as they get minimally transferred across the placenta, in comparison to regular human insulin in achieving targeted glucose values and minimizing the risk for macrosomia. ${ }^{42}$ Because the insulin analogs have shorter duration of action and more rapid onset of action than regular insulin, they are associated with improved postprandial glycemic control and less postprandial hypoglycemia. ${ }^{43}$ There are limited data on the use of long-acting insulins in pregnancy. For women with GDM who require insulin, isophane is therefore, the intermediate-acting insulin of choice (Table 4).

\section{Oral Hypoglycemic Agents}

Oral hypoglycemic agents used in the management of GDM should be both effective and safe for the woman and developing fetus. With the exception of glyburide and metformin, oral hypoglycemic drugs are generally not recommended due to concerns about potential teratogenicity or prolonged neonatal hypoglycemia from drug transport across the placenta. ${ }^{4}$

\section{Glyburide}

Glyburide, one of the two oral hypoglycemic drugs used for the management of GDM, acts primarily to enhance insulin secretion by the pancreas. Studies have shown that glyburide, unlike other sulfonylureas, does not cross the placenta. ${ }^{45}$ Certain factors are associated with higher rates of success with glyburide therapy, including initiation after 30 weeks gestation or fasting blood glucose levels $<110 \mathrm{mg} / \mathrm{dL}$ and 1-hour postprandial glucose levels $<140 \mathrm{mg} / \mathrm{dL} .{ }^{46}$ Despite several studies supporting the efficacy and safety of glyburide for women with GDM, ACOG, and ADA guidelines do not recommend its use until larger randomized controlled trials are completed on the subject. ${ }^{47}$

\section{Metformin}

Metformin is another oral hypoglycemic agent considered a potential substitute for insulin in GDM management. In a randomized controlled trial involving women with GDM, the use of metformin, whether alone or with supplemental insulin, was not associated with increased perinatal complications compared with insulin alone. ${ }^{48}$ A meta-analysis done in 2013 revealed that metformin is comparable to insulin regarding glycemic control and neonatal outcomes. ${ }^{49}$ In another recent study, metformin use was associated with similar desirable outcomes when compared with MNT and insulin use..$^{50}$

\section{Glucose Monitoring}

In patients requiring insulin, the ideal frequency for glucose monitoring has not been established. In common practice, the patient generally checks glucose levels four times a day: Once upon waking in the morning, before meals, before bed, and 1 or 2 hours postprandial, to ensure adequate glycemic control. Postprandial glucose levels are preferable to fasting glucose levels, because they are more strongly associated with macrosomia. Insulin dose adjustments based on postprandial glucose levels rather than preprandial levels were shown to be associated with improvement in glycemic control and reduction of both maternal and fetal adverse outcomes. ${ }^{51}$

For women with diet-controlled GDM, there are no clinical guidelines regarding the frequency of monitoring. The general practice involves checking glucose levels two times per day at least 2 days per week; when two values exceed the limits over the course of a week, pharmacotherapy is recommended. Urine glucose monitoring is not useful in these patients.

\section{INTRAPARTUM MANAGEMENT}

During labor, women on pharmacological therapy require hourly evaluations of their glucose values, while those with diet-controlled GDM do not require active glucose management. Patients on insulin therapy should be monitored by intermittent glucose monitoring and insulin should be administered based on sliding scale.

\section{Delivery}

There is no definitive data on the timing delivery for pregnant women with GDM. If the patient has normal or near normal glucose values, it is recommended that she should be delivered at term. The general recommendation is that pregnancies complicated by GDM should not extend beyond term. Elective cesarean section has not been associated with significant reduction of birth trauma and has not been found to be cost-effective. ${ }^{52}$ Earlier delivery was associated with reduction in chances of developing macrosomia but not with reduction of other neonatal complications. ${ }^{53}$

\section{POSTPARTUM MANAGEMENT}

After delivery, insulin resistance usually resolves quickly, as does the need for pharmacological management. However, approximately 50 to $60 \%$ of affected women 
will develop type II DM later in life. They are also at an increased risk of recurrent GDM that presents earlier in future pregnancies. An OGTT should be performed 6 weeks postpartum, 1 year post-delivery, and every 3 years thereafter.

\section{CONCLUSION}

Gestational diabetes mellitus is associated with both maternal and fetal complications. Screening and managing women at appropriate gestational age is important to minimize adverse outcomes. Glycemic control can safely be achieved with a combination of nutritional and pharmacological interventions. Metformin and glyburide have been shown to be as effective as insulin in the management of GDM. Effective communication between physician, patient, and primary care provider is essential, for better management and successful outcome in GDM mothers.

\section{REFERENCES}

1. Metzger BE, Coustan DR. Summary and recommendations of the fourth international workshop-conference on gestational diabetes mellitus. The Organizing Committee. Diabetes Care 1998 Aug;21(Suppl 2):B161-B167.

2. Expert Committee on the Diagnosis and Classification of Diabetes Mellitus. Report of the expert committee on the diagnosis and classification of diabetes mellitus. Diabetes Care 2003 Jan;26(Suppl 1):S5-S20.

3. National Diabetes Information Clearinghouse (NIDC). "Diabetes Overview" National Diabetes Information Clearinghouse. Bethesda (MD): NIH Publication; 2008.

4. Seshiah V, Balaji V, Balaji MS, Sanjeevi CB, Green A. Gestational diabetes mellitus in India. J Assoc Physicians India 2004 Sep;52:707-711.

5. Wendland EM, Torloni MR, Falavigna M, Trujillo J, Dode MA, Campos MA, Duncan BB, Schmidt MI. Gestational diabetes and pregnancy outcomes-a systematic review of the World Health Organization (WHO) and the International Association of Diabetes in Pregnancy Study Groups (IADPSG) diagnostic criteria. BMC Pregnancy Childbirth 2012 Mar;12:23.

6. Mpondo BC, Ernest A, Dee HE. Gestational diabetes mellitus: challenges in diagnosis and management. J Diabetes Metab Disord 2015 May; 14:42.

7. Cheung KW, Wong SF. Gestational diabetes mellitus update and review of the literature. Reproductive Sys Sexual Disord 2012;S2(002):1-6.

8. International Diabetes Federation. IDF diabetes atlas. 7th ed. Brussels: International Diabetes Federation; 2015.

9. Dornhorst A, Paterson CM, Nicholls JS, Wadsworth J, Chiu DC, Elkeles RS, Johnston DG, Beard RW. High prevalence of gestational diabetes in women from ethnic minority groups. Diabet Med 1992 Nov;9(9):820-825.

10. American Diabetes Association. Gestational diabetes mellitus. Diabetes Care 2004 Jan;27(Suppl 1):S88-S90.

11. Beckles, GL.; Thompson-Reid, PE; editors. Diabetes and women's health across the life stages: a public health perspective. Silver Spring (MD): Centers for Disease Control and Prevention; 2006.
12. Raja MW, Baba TA, Hanga AJ, Bilquees S, Rasheed S, Haq IU, Khan SS, Bhasir A. A study to estimate the prevalence of gestational diabetes mellitus in an urban block of Kashmir valley (North India). Int J Med Sci Public Health 2014 Jan;3(2): 191-195.

13. Swami SR, Mehetre R, Shivane V, Bandgar TR, Menon PS, Shah NS. Prevalence of carbohydrate intolerance of varying degrees in pregnant females in western India (Maharashtra) a hospital-based study. J Indian Med Assoc 2008 Nov;106(11): 712-714.

14. Bhatt AA, Dhore PB, Purandare VB, Sayyad MG, Mandal MK, Unnikrishnan AG. Gestational diabetes mellitus in rural population of Western India-results of a community survey. Indian J Endocrinol Metab 2015 Jul-Aug;19(4):507-510.

15. Nallaperumal S, Bhavadharini B, Mahalakshmi MM, Maheswari K, Jalaja R, Moses A, Anjana RM, Deepa M, Ranjani H, Mohan V. Comparison of the World Health Organization and the International Association of Diabetes and Pregnancy Study Groups criteria in diagnosing gestational diabetes mellitus in South Indians. Indian J Endocrinol Metab 2013 Sep-Oct;17(5):906-909.

16. Arora GP, Thaman RG, Prasad RB, Almgren P, Brons C, Groop LC, Vaag AA. Prevalence and risk factors of gestational diabetes in Punjab, North India: results from a population screening program. Eur J Endocrinol 2015 Aug;173(2):257-267.

17. Gopalakrishnan V, Singh R, Pradeep Y, Kapoor D, Rani AK, Pradhan S, Bhatia E, Yadav SB. Evaluation of the prevalence of gestational diabetes mellitus in North Indians using the International Association of Diabetes and Pregnancy Study groups (IADPSG) criteria. J Postgrad Med 2015 Jul-Sep;61(3):155-158.

18. O'Sullivan JB, Mahan CM, Charles D, Dandrow RV. Screening criteria for high-risk gestational diabetic patients. Am J Obstet Gynecol 1973 Aug;116(7): 895-900.

19. Cosson E, Benchimol M, Carbillon L, Pharisien I, Paries J, Valensi P, Lormeau B, Bolie S, Uzan M, Attali JR. Universal rather than selective screening for gestational diabetes mellitus may improve fetal outcomes. Diabetes Metab 2006 Apr;32(2):140-146.

20. Marquette GP, Klein VR, Niebyl JR. Efficacy of screening for gestational diabetes. Am J Perinatol 1985 Jan;2(1):7-9.

21. Dietrich ML, Dolnicek TF, Rayburn WF. Gestational diabetes screening in a private, Midwestern American population. Am J Obstet Gynecol 1987 Jun;156(6):1403-1408.

22. Williams CB, Iqbal S, Zawacki CM, Yu D, Brown MB, Herman WH. Effect of selective screening for gestational diabetes. Diabetes Care 1999 Mar;22(3):418-421.

23. Agarwal MM, Dhatt GS, Punnose J, Zayed R. Gestational diabetes: fasting and postprandial glucose as first prenatal screening tests in a high-risk population. J Reprod Med 2007 Apr;52(4):299-305.

24. Cheng YW, Block-Kurbisch I, Caughey AB. Carpenter-Coustan criteria compared with the national diabetes data group thresholds for gestational diabetes mellitus. Obstet Gynecol 2009 Aug;114(2 Pt 1):326-332.

25. American Diabetes Association. Gestational diabetes mellitus. Diabetes Care 2003 Jan;26(Suppl 1):S103-S105.

26. Lindsay MK, Graves W, Klein L. The relationship of one abnormal glucose tolerance test value and pregnancy complications. Obstet Gynecol 1989 Jan;73(1):103-106.

27. Pennison EH, Egerman RS. Perinatal outcomes in gestational diabetes: a comparison of criteria for diagnosis. Am J Obstet Gynecol 2001 May;184(6):1118-1121. 
28. Crowther CA, Hiller JE, Moss JR, McPhee AJ, Jeffries WS, Robinson JS; Australian Carbohydrate Intolerance Study in Pregnant Women (ACHOIS) Trial. Effect of treatment of gestational diabetes mellitus on pregnancy outcomes. N Engl J Med 2005 Jun;352(24):2477-2486.

29. Langer O. A spectrum of glucose thresholds may effectively prevent complications in the pregnant diabetic patient. Semin Perinatol 2002 Jun;26(3):196-205

30. Metzger BE, Buchanan TA, Coustan DR, De Leiva A, Dunger DB, Hadden DR, Hod M, Kitzmiller JL, Kjos SL, Oats JN, et al. Summary and recommendations of the Fifth International Workshop-Conference on Gestational Diabetes Mellitus. Diabetes Care 2007 Jul;30(Suppl 2):S251-S260.

31. Langer O, Conway DL. Level of glycemia and perinatal outcome in pregestational diabetes. J Matern Fetal Med 2000 Jan-Feb;9(1):35-41.

32. Langer O, Levy J, Brustman L, Anyaegbunam A, Merkatz R, Divon M. Glycemic control in gestational diabetes mellitushow tight is tight enough: small for gestational age versus large for gestational age? Am J Obstet Gynecol 1989 Sep;161(3): 646-653.

33. Thomaz LH, Lopes RE, Ribeiro Neves PA, Corrêa Monteiro Machado R, Mello de Oliveira L, Saunders C. Systematic review-nutritional therapy in gestational diabetes mellitus. Nutr Hosp 2013 Nov;28(6):1806-1814.

34. Clapp JF. Effect of dietary carbohydrate on the glucose and insulin response to mixed caloric intake and exercise in both non-pregnant and pregnant women. Diabetes Care 1998 Aug;21(Suppl 2):B107-B112.

35. Knopp RH, Magee MS, Raisys V, Benedetti T. Metabolic effects of hypocaloric diets in management of gestational diabetes. Diabetes 1991 Dec;40(Suppl 2):165-171.

36. Rizzo TA, Dooley SL, Metzger BE, Cho NH, Ogata ES, Silverman BL. Prenatal and perinatal influences on long-term psychomotor development in offspring of diabetic mothers. Am J Obstet Gynecol 1995 Dec;173(6):1753-1758.

37. Jovanovic-Peterson L, Durak EP, Peterson CM. Randomized trial of diet versus diet plus cardiovascular conditioning on glucose levels in gestational diabetes. Am J Obstet Gynecol 1989 Aug;161(2):415-419.

38. Halse RE, Wallman KE, Newnham JP, Guelfi KJ. Home-based exercise training improves capillary glucose profile in GDM women. Med Sci Sports Exerc 2014 Sep;46(9):1702-1709.

39. Magon N, Seshiah V. Gestational diabetes mellitus: noninsulin management. Indian J Endocrinol Metab 2011 Oct;15(4): 284-293.
40. Nicholson W, Bolen S, Witkop CT, Neale D, Wilson L, Bass E. Benefits and risks of oral diabetes agents compared with insulin in women with gestational diabetes: a systematic review. Obstet Gynecol 2009 Jan;113(1):193-205.

41. Magon N, Seshiah V. Gestational diabetes mellitus: insulinic management. J Obstet Gynaecol India 2014 Apr;64(2):82-90.

42. Lapolla A, Dalfra MG, Fedele D. Insulin therapy in pregnancy complicated by diabetes: are insulin analogues a new tool? Diabetes Metab Res Rev 2005 May-Jun;21(3):241-252.

43. González C, Santoro S, Salzberg S, Di Girolamo G, Alvariñas J. Insulin analogue therapy in pregnancies complicated by diabetes mellitus. Expert Opin Pharmacother 2005 May;6(5): 735-742.

44. Ziegler MH, Grafton TF, Hansen DK. The effect of tolbutamide on rat embryonic development in vitro. Teratology 1993 Jul;48(1):45-51.

45. Koren G. Glyburide and fetal safety; transplacental pharmacokinetic considerations. Reprod Toxicol 2001 MayJun;15(3):227-229.

46. Chmait R, Dinise T, Moore T. Prospective observational study to establish predictors of glyburide success in women with GDM. J Perinatol 2004 Oct;24(10):617-622.

47. American College of Obstetricians and Gynecologists Committee on Practice Bulletins-Obstetrics. Clinical management guidelines for obstetrician-gynaecologists. Gestational diabetes. Obstet Gynecol 2001 Sep;98(3):525-538

48. Rowan JA, Hague WM, Gao W, Battin MR, Moore MP. Metformin versus insulin for the treatment of gestational diabetes. N Engl J Med 2008 May;358(19):2003-2015.

49. Gui J, Liu Q, Feng L. Metformin vs insulin in the management of gestational diabetes: a meta-analysis. PLoS One 2013 May;8(5):e64585.

50. Marques P, Carvalho MR, Pinto L, Guerra S. Metformin safety in the management of gestational diabetes. Endocr Pract 2014 Oct;20(10):1022-1031

51. De Veciana M, Major CA, Morgan MA, Asrat T, Toohey JS, Lien JM, Evans AT. Post-prandial versus pre-prandial blood glucose monitoring in women with gestational diabetes mellitus requiring insulin therapy. N Engl J Med 1995 Nov;333(19): 1237-1241.

52. Rouse DJ, Owen J, Goldenberg RL, Cliver SP. The effectiveness and costs of elective caesarean delivery for fetal macrosomia diagnosed by ultrasound. JAMA 1996 Nov;276(18): 1480-1486.

53. Boulvain $\mathrm{M}$, Stan $\mathrm{C}$, Irion O. Elective delivery in diabetic pregnant women. Cochrane Database Syst Rev 2001;2:CD001997. 